\title{
Frequência da irrigação ao final da produção em mudas de espécies lenhosas
}

\author{
Irrigation frequency at final cycle of hardwood seedling production
}

\section{Priscilla Oro, João Alexandre Lopes Dranski, Ubirajara Contro Malavasi* e Marlene de Matos Malavasi}

\author{
Recebido em 30/11/2015 / Aceito em 01/04/2016
}

\section{RESUMO}

O ensaio quantificou os efeitos da frequência de irrigação ao final da produção em mudas de Enterolobium contortisiliquum e Peltophorum dubium. O experimento seguiu o delineamento inteiramente ao acaso composto por seis frequências de irrigação com cinco repetições de dez mudas. As quantificações incluíram alterações morfométricas, integridade das membranas de tecidos radiculares, e a sobrevivência sob estresse hídrico após transplante para vasos. A irrigação diária por 15 dias seguida de irrigação a cada 3 dias durante 15 dias em mudas de ambas as espécies promoveu redução no crescimento primário, alterou a alocação de biomassa seca entre tecidos aéreos e radiculares, resultou em maior integridade das membranas do sistema radicular, e aumentou a sobrevivência sobre estresse hídrico. A quantificação da integridade das membranas do sistema radicular através da aferição da condutividade elétrica externou boa previsão da sobrevivência.

PALAVRAS-CHAVE: estresse hídrico, turno de irrigação, condutividade elétrica.

\section{ABSTRACT}

This study aimed to quantify the effects of irrigation frequency at the end of the cultivation of Enterolobium contortisiliquum and Peltophorum dubium seedlings. The study followed a completely randomized design with six irrigation frequencies of five replications of ten seedlings. Daily irrigation for 15 days was followed by irrigation every 3 days for 15 days in seedlings of both species and resulted in the reduction of height growth, altered partitioning of below and above ground dry biomass, high integrity of cell membranes from root tissue, and increased seedling survival under water stress. Quantification of cell membrane integrity from root tissue through conductivity showed good prediction of seedling survival.

KEYWORDS: water stress, irrigation schedule, electric conductivity.

\section{INTRODUÇÃO}

A sobrevivência, o estabelecimento, os tratos culturais e o crescimento inicial de mudas de espécies lenhosas de interesse florestal dependem da adaptação às intempéries e às variações climáticas (CLOSE et al. 2005).

O maior ou menor sucesso do plantio de mudas produzidas em tubetes é modulado pelo regime de crescimento e técnicas no viveiro (DAVIS \& JACOBS 2005) que permitam a sobrevivência das mudas a campo evitando o replantio e gastos desnecessários na implantação do povoamento (GOMES et al. 2002).

As respostas das plantas à redução da disponibilidade de água são complexas pois afetam praticamente todos os processos do metabolismo vegetal, incluindo modificações anatômicas, morfológicas, fisiológicas e bioquímicas (JACOBS \& LANDIS 2009).

A manutenção da integridade e da estabilidade celular pode ser considerada um dos melhores indicadores fisiológicos da tolerância ao estresse hídrico (KOCHEVA et al. 2004). O dano nas membranas celulares resultante de um estresse abiótico pode ser facilmente quantificado através da liberação de eletrólitos dos tecidos vegetais (KOCHEVA et al. 2005). A perda de seletividade das membranas pelo aumento na atividade de enzimas hidrolíticas resulta na degradação da membrana plasmática. Aquela perda de seletividade resulta em cátions monovalentes e divalentes difundem-se com maior facilidade para um meio menos concentrado, aumentando os valores da

Universidade Estadual do Oeste do Paraná, Cascavel, PR, Brasil.

*Autor para correspondência <biramalavasi@yahoo.com.br> 
condutividade elétrica (WILSON \& JACOBS 2004).

O ensaio objetivou quantificar os efeitos da frequência de irrigação ao final do ciclo de produção em mudas de Enterolobium contortisiliquum [(Vell.) Morong] e Peltophorum dubium [(Spreng.) Taub] submetidas ao déficit hídrico após transplante para vasos.

\section{MATERIAL E MÉTODOS}

O ensaio utilizou casa de sombra $(50 \%$ de sombreamento) localizada no oeste do Estado do Paraná, com altitude de $420 \mathrm{~m}$ e coordenadas geográficas de $24^{\circ} 33^{\prime} 40^{\prime}$ ' S e de $54^{\circ} 04^{\prime} 00^{\prime}$ ' O.

Para a produção das mudas foram utilizadas sementes de E. contortisiliquum e $P$. dubium coletadas de frutos maduros em cinco árvores adultas localizadas em fragmentos vegetacionais da região, submetidas à superação da dormência com ácido sulfúrico concentrado por $15 \mathrm{~min}$. (MALAVASI \& MALAVASI 2004) seguido de lavagem em água corrente por igual período.

A produção totalizou 360 mudas de cada espécie produzidas via semeadura direta em tubetes cônicos de $120 \mathrm{~cm}^{3}$ preenchidos com substrato comercial a base de casca de pinus $\left(\right.$ Plantmax $\left.^{\circledR}\right)$. O substrato recebeu a adição de $4 \mathrm{~kg}$ por metro cúbico de NPK (10-1010), e posterior fertilização de cobertura com $2 \mathrm{~kg}$ de NPK (10-0-10) dissolvido em 10.000 L de água até as mudas atingirem a altura entre 18 e $23 \mathrm{~cm}$. Os tubetes foram acondicionados em bandejas plásticas com capacidade de 96 tubetes e mantidos sobre uma estrutura metálica a 1 metro do solo com temperatura e umidade do ar monitoradas diariamente.

Antes da imposição dos tratamentos, sessenta mudas de cada espécie foram aleatoriamente selecionadas, mensuradas quanto a altura e o diâmetro do coleto e posteriormente utilizadas para quantificação da biomassa seca de raízes (MSR), tecidos aéreos (MSA) e foliar (MSF) através da secagem em estufa com circulação de ar a $65^{\circ} \mathrm{C}$ até peso constante.

Os tratamentos consistiram de irrigação diária por 30 dias (T1 ou controle), irrigação diária durante 15 dias seguido de irrigação a cada 2 dias por 15 dias (T2), irrigação diária por 15 dias seguido de irrigação a cada 3 dias por 15 dias (T3), irrigação diária por 15 dias seguido de irrigação a cada 4 dias por 15 dias (T4), irrigação diária por 7 dias seguido de irrigação a cada 2 dias por 21 dias (T5), e irrigação diária por 7 dias seguido de irrigação a cada 3 dias por 21 dias (T6) em cinco repetições de dez mudas por tratamento. A irrigação foi executada por aspersão (aspersor tipo bailarina com vasão de $26,0 \mathrm{~L} \mathrm{~h}^{-1}$ ) no horário entre 16 e $17 \mathrm{~h}$ até saturação do substrato com escoamento da água pela abertura inferior dos tubetes.

Ao final da aplicação dos tratamentos, foram obtidos os valores da altura e do diâmetro do coleto e calculados os respectivos incrementos. Duas mudas de cada repetição por espécie foram selecionadas aleatoriamente para quantificações da massa seca aérea (MSA), foliar (MSF) e radicular (MSR) com cálculo dos respectivos incrementos e da razão MSA/ MSR. Naquela mesma ocasião, o teste de integridade das membranas celulares em tecidos radiculares adaptado da metodologia de WILNER (1955) foi realizado em duas mudas de cada uma das cinco por repetição.

Vinte e quatro mudas de cada espécie (repetições) foram aleatoriamente selecionadas para teste de sobrevivência ao estresse hídrico. As mudas selecionadas foram transplantadas para vasos de plástico preto de $5 \mathrm{~L}$ preenchidos com areia seca peneirada em malha de $2 \mathrm{~mm}$. Os vasos foram mantidos sob completa restrição hídrica em ambiente protegido, segundo metodologia adaptada de RITCHIE et al. (2010). A sobrevivência foi avaliada aos 15, 30 e 45 dias após o transplante (DAT). As mudas foram consideradas mortas quando apresentaram $100 \%$ de abscisão foliar com caules secos e inclinados.

$\mathrm{O}$ ensaio foi conduzido em delineamento inteiramente casualizado e os dados foram submetidos aos testes de normalidade da distribuição dos resíduos de Lilliefors e da homogeneidade da variância de Bartlet, seguido da análise de variância com o uso do aplicativo SAEG 9.1. As médias das variáveis morfométricas das mudas submetidas aos tratamentos com irrigação diária nos 15 dias iniciais (T2, T3 e T4) e dos tratamentos com irrigação diária nos 7 dias iniciais (T5 e T6) foram comparadas separadamente com o tratamento controle (T1) pelo teste de Tukey a $5 \%$ de probabilidade de erro. Os resultados de sobrevivência das mudas de cada espécie em vasos foram analisados através do teste de paralelismo entre regressões lineares de acordo com DIXON \& MASSEY JUNIOR (1969).

\section{RESULTADOS E DISCUSSÃO}

A imposição dos tratamentos em mudas de $E$. 
contortisiliquum ocorreu em dezembro de 2011 e o teste de sobrevivência em vasos de janeiro a fevereiro de 2012 enquanto que em mudas de $P$. dubium os tratamentos foram impostos em março de 2012 com o teste em vasos de abril a maio de 2012 (Figura 1).

As médias da temperatura e da umidade relativa durante o período de imposição dos tratamentos em mudas de E. contortisiliquum foi $25{ }^{\circ} \mathrm{C}$ e $66 \%$, enquanto que com mudas de $P$. dubium foi de $20^{\circ} \mathrm{C} \mathrm{e}$ $78 \%$, respectivamente.

$\mathrm{Na}$ região oeste do Paraná, os principais entraves para o sucesso do estabelecimento de povoamentos florestais é a precipitação irregular, ocorrendo períodos de estiagem durante a janela de plantio (NERY 2002). Portanto, a produção de mudas condicionadas a períodos de deficiência hídrica pode aumentar o sucesso do plantio.

O estresse hídrico induz a alterações no metabolismo vegetal dependendo do genótipo, da duração, da severidade e do estádio de desenvolvimento, ocasionando mudanças na alocação de foto-assimilados e nos mecanismos de adaptação e de resistência (PORTES et al. 2006). A redução na altura das mudas e o aumento no diâmetro de coleto são atributos que tem servido como indicadores da boa qualidade em mudas de espécies lenhosas (DRANSKI 2013; VOLKWEIS et al. 2014).

Segundo RITCHIE et al. (2010), numerosos estudos mostram que o diâmetro do coleto é o melhor indicador do desempenho após o plantio dependendo das condições edafoclimáticas. Os menores incrementos em altura foram calculados com dados de mudas de E. contortisiliquum que receberam irrigação diária durante 15 dias seguido de irrigação a cada 2 dias (T2) e a cada 3 dias por 15 dias (T3), resultando na redução de $42 \%$ na velocidade de crescimento em altura (Tabela 1). Em mudas de P. dubium a redução na velocidade de crescimento

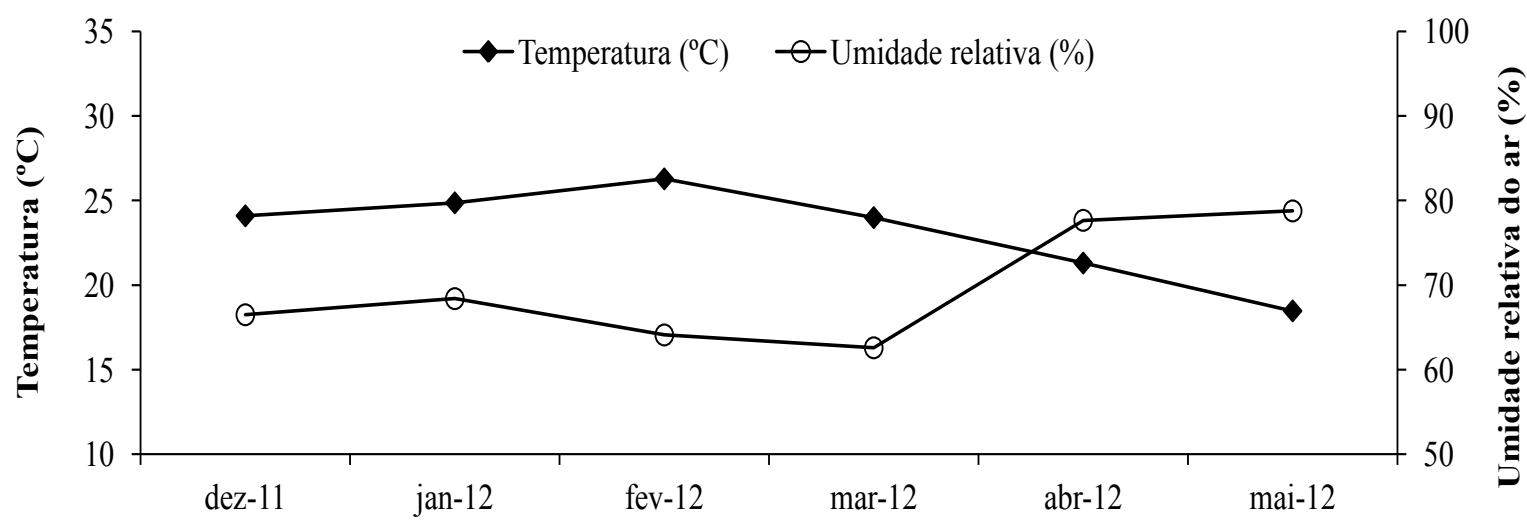

Figura 1 - Temperatura e umidade relativa do ar de dezembro/2011 a maio/2012 no local do ensaio, Marechal Cândido Rondon, PR.

Figure 1 - Temperature and relative humidity from December 2011 to May 2012 in the study location, Marechal Cândido Rondon, PR.

Tabela 1 - Incremento na altura (IA) e no diâmetro do coleto (ID) em função da frequência de irrigação e da espécie.

Table 1 - Increments in height (IA) and stem diameter (ID) as a function of irrigation frequency and species.

\begin{tabular}{lcccc}
\hline \multirow{2}{*}{ Frequência de irrigação } & \multicolumn{2}{c}{$\mathrm{IA}(\mathrm{cm})$} & \multicolumn{2}{c}{$\mathrm{ID}(\mathrm{mm})$} \\
\cline { 2 - 5 } & $\mathrm{sp}_{1}$ & $\mathrm{sp}_{2}$ & $\mathrm{sp}_{1}$ & $\mathrm{sp}_{2}$ \\
\hline T1 & $0,31 \mathrm{a}^{*}$ & $0,83 \mathrm{a}$ & $0,26 \mathrm{~b}$ & $0,20 \mathrm{~b}$ \\
$\mathrm{~T} 2$ & $0,21 \mathrm{bc}$ & $0,69 \mathrm{~b}$ & $0,40 \mathrm{a}$ & $0,33 \mathrm{a}$ \\
T3 & $0,15 \mathrm{c}$ & $0,40 \mathrm{~d}$ & $0,37 \mathrm{a}$ & $0,27 \mathrm{~b}$ \\
T4 & $0,24 \mathrm{~b}$ & $0,49 \mathrm{~cd}$ & $0,25 \mathrm{~b}$ & $0,36 \mathrm{a}$ \\
\hline & & & & \\
\hline T1 & $0,31 \mathrm{a}$ & $0,83 \mathrm{a}$ & $0,26 \mathrm{a}$ & $0,20 \mathrm{a}$ \\
T5 & $0,26 \mathrm{ab}$ & $0,62 \mathrm{bc}$ & $0,22 \mathrm{a}$ & $0,24 \mathrm{a}$ \\
T6 & $0,25 \mathrm{~b}$ & $0,70 \mathrm{~b}$ & $0,18 \mathrm{a}$ & $0,26 \mathrm{a}$ \\
\hline
\end{tabular}

${ }^{*}$ Médias seguidas de diferentes letras nas colunas diferem entre si pelo teste de Tukey a $5 \%$ de probabilidade de erro. $\mathrm{sp}_{1}=$ E. contortisiliquum, $\mathrm{sp}_{2}=P$. dubium. 
foi de $34 \%$ em comparação ao tratamento controle, quando do uso de irrigação diária por 15 dias seguido de irrigação a cada 3 dias (T3) ou a cada 4 dias por 15 dias (T4).

Mudas de ambas as espécies não externaram efeito $(\mathrm{p}>0,05)$ dos tratamentos de irrigação T5 e T6 sobre o incremento no diâmetro do coleto. Em mudas em E. contortisiliquum os maiores incrementos no diâmetro do coleto foram calculados em resposta aos tratamentos T2 $(0,40 \mathrm{~mm})$ e T3 $(0,37 \mathrm{~mm})$ e em mudas de $P$. dubium em resposta aos tratamentos T2 $(0,33 \mathrm{~mm})$ e T4 $(0,36 \mathrm{~mm})$ resultando em um aumento médio de $48 \%$ e $30 \%$, respectivamente, em relação ao tratamento controle (irrigação diária).

A tolerância vegetal ao déficit hídrico reflete as interações entre o suprimento, a demanda e a regulação de água (HAASE 2008). O manejo hídrico induz a alterações no metabolismo vegetal dependendo do genótipo, duração, severidade e do estádio de desenvolvimento (PORTES et al. 2006). Algumas das evidências em estudos de condicionamento a deficiência hídrica (VILLAR-SALVADOR et al. 2004; BAÑON et al. 2006; THOMAS 2009) revelaram alterações na condutância estomática, ajustamento osmótico, assimilação líquida de $\mathrm{CO}_{2}$ e redução no crescimento da parte aérea com maior percentual de raízes. A irrigação modula aspectos morfofisiológicos relacionados à rusticidade de mudas como exposto por TATAGIBA (2006) com a redução no incremento do coleto em diferentes clones de eucalipto submetidos ao estresse hídrico, KLIPPEL et al. (2014) em mudas do híbrido E. urograndis, e SCALON et al. (2011) em mudas de Guazuma ulmifolia Lam.

Segundo RITCHIE et al. (2010), numerosos estudos mostraram que o diâmetro do coleto é o melhor indicador do desempenho após o plantio dependendo das condições edafoclimáticas. Adicionalmente, ANTONIAZZI et al. (2013) reportaram que mudas com maiores dimensões expressam maior sobrevivência. Contrário ao retro mencionado, ZIDA et al. (2008) na África com Acacia macrostachya Reichenb. ex DC e Pterocarpus erinaceus Poir e PEZZUTTI \& CALDATO (2011) na Argentina com Pinus taeda L. concluíram que o diâmetro das mudas não afetou a sobrevivência e o crescimento a campo.

A análise dos resultados indicou que o tratamento $\mathrm{T} 3$ resultou em mudas com maior incremento na massa seca radicular (Tabela 2) em mudas de E. contortisiliquum (460 mg) e de P. dubium (1.120 mg). Segundo TAIZ \& ZEIGER (2013) um ligeiro ressecamento do solo causa um aumento na concentração de ácido abscísico (ABA) no xilema, provavelmente produzido na coifa das raízes, que além de promover o crescimento das raízes e a formação de raízes laterais é transportado e redistribuído para outras partes do vegetal, resultando no fechamento estomático, na diminuição da expansão celular foliar e na osmo-regulação.

$\mathrm{O}$ efeito das várias frequências de irrigação em mudas de E. contortisiliquum (Tabela 2) oportunizou maior incremento da massa seca aérea $(440 \mathrm{mg})$ em mudas submetidas a irrigação diária por 15 dias seguido de irrigação a cada 3 dias (T3). Em mudas de $P$. dubium, os incrementos na massa seca aérea não foram alterados (T2, T3 e T4) ou foram reduzidos (T5 e T6) em relação as mudas do tratamento controle. As diferenças de comportamento no acúmulo de MSA nas mudas das espécies testadas pode resultar das diferenças de rota evolutiva entre E. contortisiliquum descrita como não pioneira na sucessão ecológica (AQUINO et al. 2009) e P. dubium considerada pioneira na sucessão ecológica (WANLI et al. 2001).

As respostas vegetais ao déficit hídrico variam conforme a espécie. ARAUJO et al. (2010) não reportaram diferenças em mudas de Mimosa caesalpiniifolia Benth em relação à alocação de matéria seca foliar e radicular quando submetidas ao déficit hídrico, enquanto que mudas de Parapiptadenia rigida [(Benth.) Brenan] externaram maiores valores de massa seca caulinar em comparação as mudas controle. A menor disponibilidade hídrica reduz a alocação de matéria seca às folhas e aumenta às raízes (JACOBS \& LANDIS 2009) o que maximiza o contato da raiz com a rizosfera pela emissão de novas radicelas e consequente aumento da superfície e da capacidade de absorção da água.

O desenvolvimento do sistema radicular vegetal está envolvido no processo de adaptação morfofisiológica em resposta ao estresse hídrico (BAÑON et al. 2006). O estresse hídrico aumenta a alocação de biomassa no sistema radicular já que as plantas tendem a investir mais em crescimento radicular para explorar um maior volume de solo, e consequentemente aumentar a capacidade de absorção de água (GROSSNICKLE 2012).

Mudas de E. contortisiliquum responderam com sensível redução na matéria seca foliar (MSF) independente da frequência de irrigação enquanto que mudas de $P$. dubium externaram maior redução em MSF quando submetidas aos tratamentos com maior 
intervalos entre as irrigações diárias. Plantas sob déficit hídrico apresentam senescência acelerada em razão da escassez de nitrogênio para suprir o crescimento. A redução da área foliar pode ser considerada estratégia de defesa contra o estresse hídrico (CORDEIRO et al. 2009) por ser importante defesa contra a perda excessiva de água. Adicionalmente, a redução na área foliar está entre as várias características xeromórficas identificadas em vegetais sob déficit hídrico (VILLAGRA e CAVAGNARO 2006).

A redução no acúmulo de matéria seca de folhas (MSF) com estresse hídrico foi reportado por CHAVES (2001) que anotou redução de $68,6 \%$ e de $31,7 \%$ em clones de eucalipto submetidos ao estresse hídrico severo e moderado, respectivamente, em resposta a abscisão foliar e a redução na expansão foliar. Em mudas de M. caesalpiniifolia cultivadas sob 100,50 e $25 \%$ da capacidade de saturação do recipiente, SANTIAGO et al. (2002) constataram redução na MSF aos 50 dias sob restrição hídrica, enquanto SCALON et al. (2011) constataram 50\% de diminuição na MSF em Guazuma ulmifolia Lam. sob disponibilidade de água de 25 e $12,5 \%$ da capacidade de campo aos 35 dias.

A análise da razão MSA/MSR ao final do período de imposição dos tratamentos não resultou em diferença $(\mathrm{p}>0,05)$ das frequências de irrigação testadas em mudas de E. contortisiliquum. Em mudas de $P$. dubium houve redução da razão MSA/MSR com o aumento no intervalo entre as irrigações diárias com o menor valor $(1,34)$ resultante da aplicação do tratamento T6 (Tabela 3).

Tabela 2 - Incrementos na massa seca radicular (MSR), aérea (MSA) e foliar (MSF) em função da frequência de irrigação e da espécie.

Table 2 - Increments of below ground (MSR), aboveground (MSA) and leaf (MSF) dry biomass as a function of irrigation frequency and species.

\begin{tabular}{|c|c|c|c|c|c|c|}
\hline \multirow{2}{*}{$\begin{array}{l}\text { Frequência } \\
\text { de irrigação }\end{array}$} & \multicolumn{2}{|c|}{ MSR (mg) } & \multicolumn{2}{|c|}{ MSA (mg) } & \multicolumn{2}{|c|}{ MSF (mg) } \\
\hline & $\mathrm{sp}_{1}$ & $\mathrm{sp}_{2}$ & $\mathrm{sp}_{1}$ & $\mathrm{sp}_{2}$ & $\mathrm{sp}_{1}$ & $\mathrm{sp}_{2}$ \\
\hline $\mathrm{T} 1$ & $200 \mathrm{c}^{*}$ & $940 \mathrm{c}$ & $210 \mathrm{c}$ & $1.370 \mathrm{a}$ & $330 a$ & $510 a$ \\
\hline $\mathrm{T} 2$ & $290 \mathrm{~b}$ & $1.030 \mathrm{~b}$ & $250 \mathrm{c}$ & $1.400 \mathrm{a}$ & $-350 b$ & $350 \mathrm{~b}$ \\
\hline $\mathrm{T} 3$ & $460 \mathrm{a}$ & $1.120 \mathrm{a}$ & $440 \mathrm{a}$ & $1.430 \mathrm{a}$ & $-270 b$ & $200 \mathrm{c}$ \\
\hline $\mathrm{T} 4$ & $280 \mathrm{~b}$ & $930 \mathrm{c}$ & $390 \mathrm{~b}$ & $1.440 \mathrm{a}$ & $-470 b$ & $50 d$ \\
\hline $\mathrm{T} 1$ & $200 \mathrm{a}$ & $940 a$ & $210 \mathrm{a}$ & $1.370 \mathrm{a}$ & $330 \mathrm{a}$ & $510 \mathrm{a}$ \\
\hline T5 & $250 \mathrm{a}$ & $790 \mathrm{~b}$ & $240 \mathrm{a}$ & $1.270 \mathrm{~b}$ & $-430 b$ & $-40 b$ \\
\hline T6 & $200 \mathrm{a}$ & $830 \mathrm{a}$ & $180 \mathrm{~b}$ & $1.110 \mathrm{c}$ & $-430 b$ & $-100 b$ \\
\hline
\end{tabular}

${ }^{*}$ Médias seguidas de diferentes letras nas colunas diferem entre si pelo teste de Tukey a 5\% de probabilidade de erro. $\mathrm{sp}_{1}=$ E. contortisiliquum $; \mathrm{sp}_{2}=P$. dubium .

Tabela 3 - Razão entre biomassa seca aérea e radicular (MSA/MSR) e biomassa total (MST) ao final da rustificação em função da frequência de irrigação e da espécie.

Table 3 - Shoot/root dry biomass ratio (MSA/MSR) and total dry mass (MST) at the end of seedling hardening as a function of irrigation frequency and species.

\begin{tabular}{lcccc}
\hline Frequência de irrigação & \multicolumn{2}{c}{ MSA/MSR } & \multicolumn{2}{c}{ MST } \\
\cline { 2 - 5 } & $\mathrm{sp}_{1}$ & $\mathrm{sp}_{2}$ & $\mathrm{sp}_{1}$ & $\mathrm{sp}_{2}$ \\
\hline T1 & $1,32 \mathrm{a}^{*}$ & $1,74 \mathrm{a}$ & $4,79 \mathrm{a}$ & $4,88 \mathrm{ab}$ \\
T2 & $1,26 \mathrm{a}$ & $1,60 \mathrm{~b}$ & $4,81 \mathrm{a}$ & $4,93 \mathrm{a}$ \\
T3 & $1,40 \mathrm{a}$ & $1,47 \mathrm{c}$ & $4,55 \mathrm{~b}$ & $4,81 \mathrm{~b}$ \\
T4 & $1,41 \mathrm{a}$ & $1,48 \mathrm{c}$ & $4,21 \mathrm{~b}$ & $4,41 \mathrm{c}$ \\
\hline & & & & \\
T1 & $1,32 \mathrm{a}$ & $1,74 \mathrm{a}$ & $4,79 \mathrm{a}$ & $4,88 \mathrm{a}$ \\
T5 & $1,09 \mathrm{a}$ & $1,46 \mathrm{~b}$ & $4,20 \mathrm{ab}$ & $4,12 \mathrm{~b}$ \\
T6 & $1,31 \mathrm{a}$ & $1,34 \mathrm{~b}$ & $3,89 \mathrm{~b}$ & $3,90 \mathrm{c}$ \\
\hline
\end{tabular}

${ }^{*}$ Médias seguidas de diferentes letras nas colunas diferem entre si pelo teste de Tukey a $5 \%$ de probabilidade de erro. $\mathrm{sp}_{1}=E$. contortisiliquum, $\mathrm{sp}_{2}=P$. dubium. 
Sob condições de estresse hídrico pode existir maior expansão das raízes devido ao secamento da superfície do solo. Alternativamente, pode haver redução no consumo de carbono e energia sem afetar completamente o sistema fotossintético e assim distribuir uma maior proporção de fotoassimilados ao sistema radicular (TAIZ \& ZEIGER 2013).

A resposta vegetal ao déficit hídrico depende dos estádios fenológicos, da genética, e da magnitude e intensidade do estresse. Um exemplo do caráter genético sobre as respostas vegetais ao déficit hídrico encontra-se em ARAUJO et al. (2010) que constataram que os maiores incrementos na massa seca radicular, aérea e foliar em mudas de Parapiptadenia rigida Bentham (Brenan) resultaram com irrigação a intervalos de 7 e 14 dias.

OLIVEIRA (2000) reportou em estudo de estresse hídrico em Annona muricata L. uma maior produção de massa seca total em mudas irrigadas sem estresse hídrico. No viveiro, diminuir as operações diárias de irrigação significa reduzir custos, principalmente com mão de obra, consumo de água e energia elétrica.

Os menores valores de incremento em MST resultaram da imposição do tratamento $\mathrm{T} 6 \mathrm{em}$ ambas as espécies (Tabela 3) o qual submeteu as mudas a irrigação a cada três dias durante 21 dias. GRIFFITHS e PARRY (2002) sugeriram que a redução na produção de MST em plantas sujeitas ao estresse hídrico é mais conspícua a medida em que a exposição ao estresse é mais prolongada. TATAGIBA (2006) reportou que o acúmulo de MST em clones de Eucalyptus foi reduzido pelo estresse hídrico ao final do ensaio enquanto VELLINI (2008) também em clones da mesma espécie obteve menor produção de massa seca em mudas irrigadas a cada seis dias em comparação com as irrigadas diariamente.

$\mathrm{O}$ teste da condutividade elétrica indicou redução no extravasamento de eletrólitos em tecidos radiculares obtidos de mudas de E. contortisiliquum submetidas aos tratamentos T2 $(7,1 \%)$ e T3 $(17,9 \%)$ em relação ao tratamento controle. Em mudas de P. dubium as reduções foram de $10,4 \%, 14,3 \%$ e $5,4 \%$ em resposta aos tratamentos T2, T3 e T4, respectivamente. Estes resultados expressam a maior integridade celular radicular como uma possível estratégia de resistência das mudas ao déficit hídrico. Raízes são órgãos frágeis e sensíveis às condições ambientais (RICHIE \& LANDIS 2006), portanto, este aumento na condutividade elétrica pode indicar possíveis danos celulares seja pela desidratação celular ou pela deformação das membranas radiculares (BAJJI et al. 2002). Segundo KOCHEVA et al. (2004), a desidratação pode ocasionar danos severos nas membranas causando um aumento na permeabilidade, e eventualmente dificultar o processo de recuperação dos tecidos após reidratação.

$\mathrm{O}$ aumento da síntese de enzimas antioxidantes e a maior deposição de substâncias osmoticamente ativas conferem maior tolerância celular. Segundo TAIZ \& ZEIGER (2013) existe aumento na atividade da enzima peroxidase que desencadeia processos fisiológicos que culminam na proteção celular contra as reações oxidativas, na lignificação da parede celular, na oxidação de compostos fenólicos, biossíntese de etileno, e na manutenção da integridade das membranas.

As avaliações obtidas deste ensaio assemelham-se aos reportados por RADOGLOU \& RAFTOYANNIS (2000), SARVAS (2003), MOLLÁ et al. (2006), RÄISÄNEN et al. (2009) e JAFFE (2012) que trabalharam com diversas espécies sob diferentes condições ambientais e constataram que a quantificação do extravasamento de eletrólitos de tecidos radiculares é consistente na avaliação do grau de integridade das membranas celulares.

Os resultados da probabilidade de significância pelos testes de normalidade de Shapiro-Wilk ( $\mathrm{P}=$ $0,062$ e $\mathrm{P}=0,116)$ e da homogeneidade da variância de Bartlet $(\mathrm{P}=0,315$ e $\mathrm{P}=0,153)$ em mudas de $E$. contortisiliquum e $P$. dubium, respectivamente, justificaram o uso dos valores percentuais do teste de sobrevivência em vasos.

A comparação dos resultados da sobrevivência através do teste de paralelismo entre regressões lineares (Tabela 4) com os resultados do teste de sobrevivência entre T1 e T2, T3 e T4, e entre T1 e T5 e T6 indicou diferença apenas entre a irrigação diária por 30 dias (T1) e a irrigação diária por 15 dias seguido de irrigação a cada 3 dias por 15 dias (T3).

A avaliação da sobrevivência de mudas produzidas em tubetes se mostra necessária pois o meio de crescimento não proporciona reserva de água suficiente para manter a muda viva por mais de uma semana no campo, podendo, esse tempo, ser ainda menor sob condições de pós-plantio quente e seco (BUZETTO et al. 2002).

Mudas de E. contortisiliquum assim como de P. dubium submetidas ao tratamento T3 externaram maior porcentagem de sobrevivência sob condições 
de déficit hídrico (Figura 2). A maior redução no percentual de mudas vivas de E. contortisiliquum resultou provavelmente das condições de alta temperatura e baixa umidade relativa do ar durante os meses de janeiro e fevereiro (Figura 1) comparado com as condições do ensaio em vasos com mudas de P. dubium.

Vários autores afirmaram que a aclimatação das mudas a partir do manejo hídrico aumenta a sobrevivência das plantas sob condições de campo (CHAVES 2001; TATAGIBA 2006; FREITAG 2007; PEREIRA et al. 2010).

$\mathrm{O}$ teste da integridade das membranas celulares mostrou ser consistente na avaliação da sobrevivência em mudas de E. contortisiliquum e de $P$. dubium sob condições de déficit hídrico tendo em vista a direção e a significância dos coeficientes de correlação calculados (Tabela 5).

As avaliações obtidas deste ensaio assemelham-se aos reportados por RADOGLOU \& RAFTOYANNIS (2000), SARVAS (2003), MOLLÁ et al. (2006), RÄISÄNEN et al. (2009) e JAFFE (2012) que trabalharam com diversas espécies sob diferentes condições ambientais e constataram que a quantificação do extravasamento de eletrólitos de tecidos radiculares é consistente na avaliação do grau de integridade das membranas celulares.

A correlação inversa entre sobrevivência e o teste de integridade das membranas também foi constatado por RADOGLOU \& RAFTOYANNIS (2001) com Fraxinus ornus L. e Castanea sativa Mill. As vantagens do teste incluem a utilização de uma

Tabela 4 - Teste de paralelismo das regressões lineares com dados da sobrevivência entre o tratamento controle (T1) com os demais tratamentos em função da espécie.

Table 4 - Parallelism test of linear regression with survival data between the control (T1) with the other treatments as a function of species.

\begin{tabular}{lcc}
\hline \multirow{2}{*}{ Frequência de irrigação } & $\mathrm{sp}_{1}$ & $\mathrm{sp}_{2}$ \\
\cline { 2 - 3 } & $\mathrm{T} 1$ & $\mathrm{~T} 1$ \\
\hline T2 & 1,51 & 1,67 \\
T3 & $3,34^{* *}$ & $2,28^{* *}$ \\
T4 & $-0,01$ & $-0,60$ \\
T5 & $-0,01$ & $-1,05$ \\
T6 & $-0,52$ & $-1,63$ \\
\hline
\end{tabular}

${ }^{*}$ Significativo a $1 \%$ pelo teste t. $\mathrm{sp}_{1}=$ E. contortisiliquum, $\mathrm{sp}_{2}=P$. dubium.

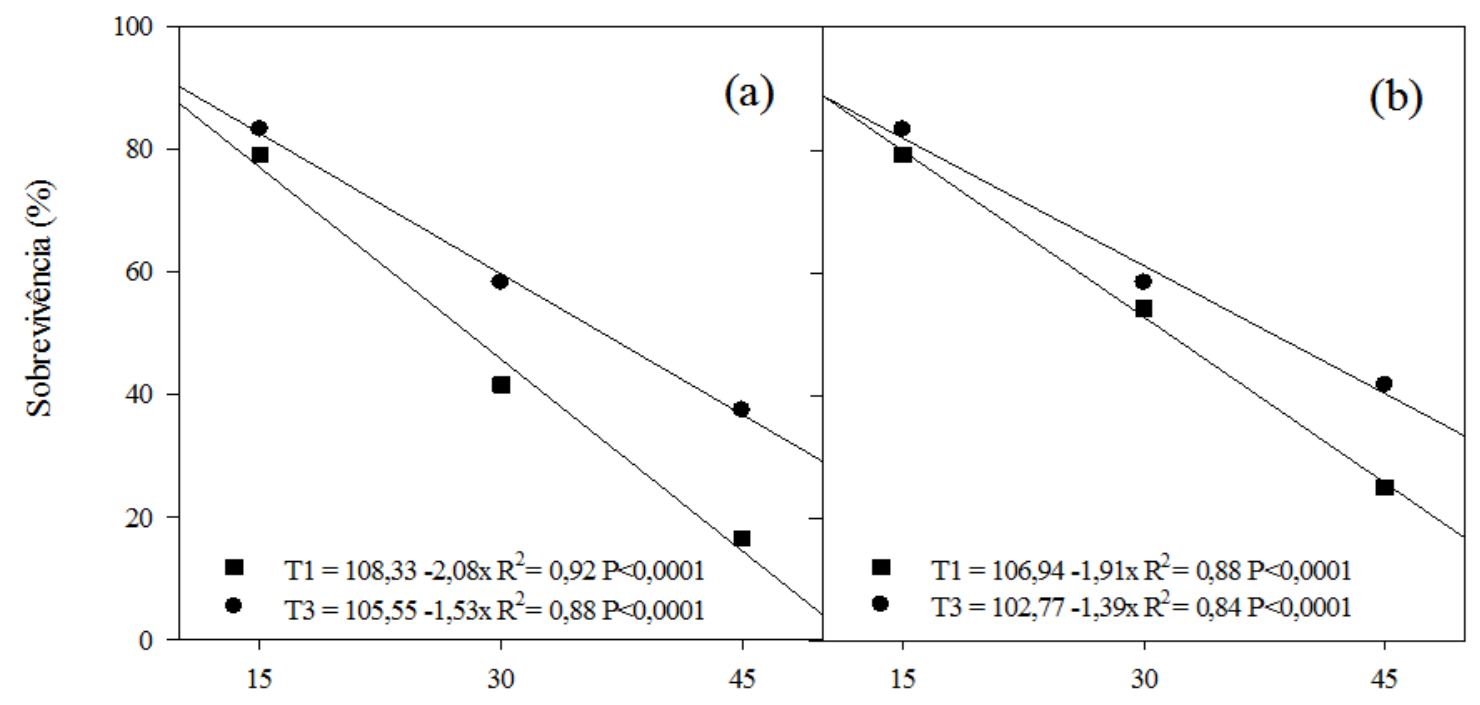

Período de tempo (dias)

Figura 2 - Sobrevivência de mudas de E. contortisiliquum (a) e P. dubium (b) em função da frequência de irrigação ao final do ciclo de produção.

Figure 2 - Survival of E. contortisiliquum (a) and P. dubium (b) seedlings as a function of irrigation frequency at the end of production cycle. 
Tabela 5 - Coeficientes de correlação simples entre o teste da integridade das membranas celulares de tecidos radiculares e a sobrevivência de mudas sob estresse hídrico.

Table 5 - Simple correlation coefficients between cell integrity test from root tissues and seedling survival under water stress.

\begin{tabular}{lcccc}
\hline \multirow{2}{*}{ Espécie } & \multirow{2}{*}{$N$} & \multicolumn{3}{c}{ Sobrevivência (\%) } \\
\cline { 3 - 5 } & 24 & 15 dias & 30 dias & 45 dias \\
\hline E. contortisiliquum & 24 & $-0,31^{\text {ns }}$ & $-0,60^{* *}$ & $-0,76^{* *}$ \\
$P$. dubium & $-0,42^{*}$ & $-0,70^{* *}$ & $-0,75^{* *}$ \\
\hline${ }^{* * *}$, ns Significativo a 1\%, a 5\% e não significativo pelo teste t.
\end{tabular}

pequena quantidade de material vegetal (RITCHIE \& LANDIS 2006), a análise de um grande número de amostras em laboratório, além de ser acurado e sensível o suficiente para reprodutibilidade dos resultados (KOCHEVA et al. 2005).

\section{CONCLUSÕES}

A irrigação diária por 15 dias seguido de irrigação a cada 4 dias por mais 15 dias em mudas de E. contortisiliquum e de $P$. dubium resultam na maior sobrevivência quando submetidas ao déficit hídrico.

$\mathrm{O}$ teste da integridade das membranas celulares dos tecidos radiculares mostrou boa correlação na avaliação da sobrevivência em mudas de $E$. contortisiliquum e de $P$. dubium submetidas ao déficit hídrico em vasos por até 45 dias.

\section{AGRADECIMENTOS}

Agradecemos a CAPES e ao CNPq pelo aporte de recursos financeiros necessários.

\section{REFERÊNCIAS}

AQUINO AFMAG et al. 2009. Superação de dormência em sementes de orelha-de-negro (Enterolobium contortisiliquum (Vell.) Morang.). Revista Verde de Agroecologia e Desenvolvimento Sustentável 4: 69-75.

ANTONIAZZI AP et al. 2013. Eficiência de recipientes no desenvolvimento de Cedrela fissilis Vell. (Meliaceae). Revista Brasileira de Biociências 11: 313-317.

ARAUJO RSL et al. 2010. Análise de crescimento em Mimosa caesalpiniifolia Benth. (sabiá) e Parapiptadenia rigida Bentham (Brenan) (angico monjolo) submetidas ao estresse hídrico. In: X Jornada de Ensino, Pesquisa e Extensão. Anais..... Recife: UFRPE. p.3.

BAJJI M et al. 2002. The use of electrolyte leakage method for assessing cell membrane stability as a water stress tolerance test in durum wheat. Plant Growth Regulation 36: 61-70.

BAÑON S et al. 2006. Hardening of oleander seedlings by déficit irrigation and low air humidity. Environmental and Experimental Botany 56: 36-43.

BUZETTO FA et al. 2002. Avaliação de um polímero adsorvente a base de acrilamida no fornecimento de água no fornecimento de água em mudas de Eucalyptus urophylla em pós-plantio. Piracicaba: IPEF, 8p. (Circular Técnica 195).

CHAVES JH. 2001. Crescimento, fotossíntese e relações hídricas de clones de eucalipto sob diferentes regimes hídricos. Dissertação (Mestrado em Ciência Florestal). Viçosa: UFV. 106p.

CLOSE DC et al. 2005. The physiological basis of containerised tree seedling 'transplant shock': a review. Australian Forestry 68: 112-120.

CORDEIRO YEM et al. 2009. Physiological and morphological responses of young mahogany (Swietenia macrophylla King) plants to drought. Forest Ecology and Management 258:1449-1455.

DAVIS AS \& JACOBS DF. 2005. Quantifying root system quality of nursery seedlings and relationship to outplanting performance. New Forests 30: 295-311.

DIXON WJ \& MASSEY JUNIOR FJ. 1969. Introduction to statistical analysis. 3.ed. Tokyo: McGraw-Hill, Kogakusha. 638p.

DRANSKI JAL et al. 2013. Effect of ethephon on hardening of Pachystroma longifolium seedlings. Revista Árvore 37: 401-407.

FREITAG AS. 2007. Frequências de irrigação para Eucalyptus grandis e Pinus elliottii em viveiro. Dissertação (Mestrado em Engenharia Agrícola). Santa Maria: UFSM. 60p.

GOMES JM et al. 2002. Parâmetros morfológicos na avaliação de qualidade de mudas de Eucalyptus grandis. Revista Árvore 26: 655-664.

GROSSNICKLE SC. 2012. Why seedlings survive: influence of plant attributes. New Forests 43: 711-738.

HAASE DL. 2008. Understanding forest seedling quality: measurements and interpretation. Tree Planters Notes 52: 24-30.

JACOBS DF \& LANDIS TD. 2009. Hardening. In: DUMROESE RK et al. Nursery manual for native plants: Guide for tribal nurseries. United States Department of Agriculture, Forest Service. p.217-239.

JAFFE MJ. 2012. Thigmomorphogenesis: electrical 
resistance and mechanical correlates of the early events of growth retardation due to mechanical stimulation in beans. Zeitschrift für Pflanzenphysiologie 78: 24-32

KLIPPEL VH et al. 2014. Impacto da deficiência hídrica no crescimento inicial de eucalipto. Revista Científica Eletrônica de Engenharia Florestal 23: 48-59.

KOCHEVA K et al. 2004. Evaluation of chlorophyll fluorescence and membrane injury in the leaves of barley cultivars under osmotic stress. Bioelectrochemistry 63: 121-124.

KOCHEVA KV et al. 2005. A diffusion approach to the electrolyte leakage from plant tissues. Physiologia Plantarum 125: 1-9.

MALAVASI UC \& MALAVASI MM. 2004. Dormancy breaking and germination of Enterolobium contortisiliquum (Vell.) Morong seed. Brazilian Archives of Biology and Technology 47: 851-854.

MOLLÁ S et al. 2006. Physiological and transplanting performance of Quercus ilex L. (holm oak) seedlings grown in nurseries with different winter conditions. Forest Ecology and Management 237: 218-226.

NERY JT et al. 2002. Correlação da precipitação do estado do Paraná com a anomalia da temperatura da superfície do mar do Pacífico Equatorial. Revista Brasileira de Agrometeorologia 10: 305-316.

OLIVEIRA DV. 2000. Aspectos do crescimento da gravioleira (Annona muricata L.) sob estresse hídrico. Dissertação (Mestrado em Botânica). Recife: UFRPE. 60p. PEREIRA MRR et al. 2010. Análise de crescimento em clones de Eucalipto submetidos à estresse hídrico. Irriga 15: 98-110.

PEZZUTTI RV \& CALDATO SL. 2011. Sobrevivência e crescimento inicial de mudas de Pinus taeda L. com diferentes diâmetros do colo. Ciência Florestal 21: 355362.

PORTES MT et al. 2006. Water deficit affects photosynthetic induction in Bauhinia forficata Link (Fabaceae) and Esenbeckia leiocarpa Engl. (Rutaceae) growing in understorey and gap conditions. Brazilian Journal of Plant Physiology 18: 491-512.

RADOGLOU K \& RAFTOYANNIS Y. 2000. A comparative study of plant vitality tests and field performance of eleven tree species. Phyton 40: 163-168.

RADOGLOU K \& RAFTOYANNIS Y. 2001. Effects of desiccation and freezing on vitality and field performance of broadleaved tree species. Annals of Forest Science 58: 59-68.

RÄISÄNEN M et al. 2009. Cold acclimation of norway spruce roots and shoots after boron fertilization. Silva Fennica 43: 223-233.

RITCHIE GA et al. 2010. Assessing plant quality. In: LANDIS TD et al. The container tree nursery manual: Seedling Processing, Storage, and Outplanting. Washington, USDA Forest Service 7: 18-81.

RICHIE GA \& LANDIS TD. 2006. Seedling quality tests: root electrolyte leakage. USDA Forest Nursery Notes, Winter 6-10.

SANTIAGO AMP et al. 2002. Crescimento de plantas jovens de Mimosa caesalpiniifolia Benth cultivada sob estresse hídrico. Revista Ecossistema 26: 23-30.

SARVAS M. 2003. Change of cold hardiness in bare-rooted norway spruce planting stock during autumn and its effect on survival. Journal of Forest Science 49: 133-139.

SCALON SPQ et al. 2011. Estresse hídrico no metabolismo e crescimento inicial de mudas de mutambo (Guazuma ulmifolia Lam.). Ciência Florestal 21: 655-662.

TAIZ L \& ZEIGER E. 2013. Fisiologia vegetal. 5. ed. Porto Alegre: Artmed. 918p.

TATAGIBA SD. 2006. Crescimento inicial, trocas gasosas e status hídrico de clones de eucalipto sob diferentes regimes de irrigação. Dissertação (Mestrado em Produção Vegetal). Alegre: UFES. 110p.

THOMAS DS. 2009. Survival and growth of drought hardened Eucaliptus pilularis Sm. seedlings and vegetative cuttings. New Forests 38: 245-259.

VILLAGRA PE \& CAVAGNARO JB. 2006. Water stress effects on the seedling growth of Prosopis argentina and Prosopis alpataco. Journal of Arid Environments 64: 390400.

VILLAR-SALVADOR P et al. 2004. Drought tolerance and transplanting performance of holm oak (Quercus ilex) seedlings after drought hardening in the nursery. Tree Physiology 24: 1147-1155.

VOLKWEIS CR et al. 2014. Efeito da tigmomorfogênese na morfometria de mudas de Maytenus ilicifolia (Schrad.) Planch. Ciência Florestal 24: 339-346.

WANLI $Z$ et al. 2001. Pré-condicionamento e seus efeitos em sementes de canafístula (Peltophorum dubium (Spreng.) Taub.). Revista Brasileira de Sementes 23: 146-153.

WILNER J. 1955. Results of laboratory tests for winter hardiness of woody plants by electrolyte methods. Proceedings of the American Society for Horticultural Science 66: 93-99.

WILSON BC \& JACOBS DF. 2004. Electrolyte leakage from stem tissue as an indicator of hardwood seedling physiological status and hardiness. In: YAUSSY DA et al. Proceedings of the $14^{\text {th }}$ Central Hardwoods Forest Conference. Wooster: USDA, p.373-381.

ZIDA D et al. 2008. Initial seedling morphological characteristics and field performance of two Sudanian savanna species in relation to nursery production period and watering regimes. Forest Ecoljaffeogy and Management 255: 2151-2162. 